\title{
Customized Product Development Supported by Integrated Information
}

\author{
Mitja VARL ${ }^{\mathrm{a}}$, Jože DUHOVNIK ${ }^{\mathrm{b}}$, and Jože TAVČAR ${ }^{\mathrm{b}, 1}$ \\ ${ }^{a}$ Kolektor ETRA, d.o.o., Ljubljana, Slovenia \\ ${ }^{\mathrm{b}}$ University of Ljubljana, Faculty of Mechanical Engineering, Ljubljana, Slovenia
}

\begin{abstract}
Information systems are key enablers for the integration and reliable management of the product development process. Information systems are the backbone that connects various sub-processes and enables flexible product customization. Fast, robust, and cost-efficient product adaptation is especially important in one-of-a-kind production. This paper presents a transformation of the product development design process for large power transformers into a competitive and smartly supported process. One-of-a-kind production is specific, as each product must be customized, wherefore a robust design process well supported by IT plays a key role in creating a digital twin and the product's final value. Based on a systematic analysis of the sample company, this paper proposes a model for the complete renewal of information systems and of working methodology, where reorganization is demonstrated in an increase of overall effectiveness.
\end{abstract}

Keywords. Engineering informatics, process integration, product development tools, lean methods, concurrent engineering, one-of-a-kind production, knowledge management

\section{Introduction}

Nowadays companies are facing intense and increasing pressure to reduce costs, establish shorter time-to-market, and increase the added value of the products by investing in their development. That pressure has led to the expansion of activities related to the development and improvement of production processes [1]. Highly individual production requires a high degree of flexibility and timely response to customer needs [2]. Accordingly, good information technology (IT) solutions play a key role in the company's operations [3]. The design process in one-of-a-kind production is characterized by the adaptation of a basic design to individual customer's requirements - adaptive design process [4]. The foundation of a robust design process is sufficient IT support, expressed in the absolute control of data related to one-of-a-kind products and the reliable retention of knowledge and experience. All the advantages provided by such information management systems are optimally developed only with a sound combination of knowledge of the working methods, concurrent reorganization of existing work, and specific upgrades, for example, to the expert system. A transdisciplinary approach is needed that considers technical and social aspects for PDP. The PLM system is an integral system of product management throughout its lifecycle. Managing multiple fields of work leads to better results than when managing those fields

${ }^{1}$ Corresponding Author, Mail: joze.tavcar@lecad.fs.uni-lj.si. 
individually [5]. Another important fact is that $80 \%$ of a project's cost is generated in its development [6]. Rogalski identifies six key aims of modern IT tools implementation: higher efficiency, shorter time-to-market, clear communication, enhanced design quality, standardized process design and efficient knowledge management [7]. Appropriate solutions are thus hiding in the development of the IT environment (development of an expert system, combining existing software tools, potential introduction of PDM and PLM systems), in the introduction of the universality and uniformity of working procedures [8], in eliminating redundant tasks (making processes lean), and in the introduction of fast, robust, real-time feedback loops to verify the partial and over-all efficiency [9], [10].

Applying IT support and knowledge management is of key importance for more efficient and robust design process [11],[12],[13]. The case of the development and production of large transformers is discussed. The result of many such years of transformation is the toolset of modern information support and knowledge management, which enables a company's competitiveness and further growth. Several supporting tools have been developed that accelerate the robust creation of a product's digital twin. The transformation itself is presented first with all the company-specific details and later in the generalized model. Therefore, the information support model presented here is the main contribution of this publication and it is applicable in most companies that need to tailor their products to individual customers. In parallel with the redesign of information support, organizational changes in the product development process (PDP) were made within the company, and a great effort was made in gaining new employee competencies. Information support is a very important tool, but it cannot replace engineers. A holistic approach is needed that includes advanced computation tools, communications with customers and suppliers, and cultural changes within an enterprise that stimulate the sharing of knowledge and the application of agile and lean methods into PDP.

\section{Model for IT support of PDP in One-of-a-Kind Production}

The IT support of PDP model is analyzed in the context of a one-of-a kind business environment. The design of each new power transformer is suited to an adaptive type of design. For example, when a new design problem arises, it is solved through the modification of an existing design rather than performing the design process from the beginning. The guidelines for IT support in OKP were drafted (Table 1) based on agile and lean methods, the CE approach, a literature review, the authors' experiences, and a detailed analysis of activities and the information flow. The proposal considers that the information involved in the product development process is complex and comes in several forms (3D models, drawings, calculations, numerical simulation, design parameters, etc.). There are also several creators and users of information in the process chain. Product development must be accelerated by applying different kind of supporting tools. There is a need to ensure a high degree of reliability in the transfer of information between different subsystems, and control mechanisms must be applied. Human involvement in knowledge recording and reuse must be integrated into IT support.

Product knowledge must be integrated into product design tools that enable fast and reliable product configurations according to specific customer needs - creation of a product's digital twin. Such tools can be implemented as a variable bill of materials that specify which building blocks are compulsory and which one are optional. All possible 
options, product pre-development and design tools are conducted already before the first customer order is confirmed. In the case of more complex products and specific requests the whole product or at least some of the modules need to be designed according to specific requests. In such cases, parametric modelling can be a helpful tool that enables not only faster design, but considers several rules and constraints for better product robustness. The background of such tools is systemic PD that considers modular structure, platform design, adaptive design, and the exchange and interchange of standard building blocks. Product family and tool development must be completed before or in parallel to the running project for customers.

Table 1: Specific requests for IT support in one-of-a-kind production.

\begin{tabular}{|c|c|}
\hline IT criteria & Way of implementation \\
\hline 1 Application of PLM system & $\begin{array}{l}\text { - } \quad \text { User-friendly way for searching similar modules, parts } \\
\text { - } \quad \text { Independent storing/documentation of modules (ready for reuse; } \\
\text { - } \quad \text { V prerequisite for internal standardization) } \\
\text { - }\end{array}$ \\
\hline $\begin{array}{l}2 \text { Computer supported work at all } \\
\text { PD phases } \\
\text { Tools and methods for adaptive } \\
\text { product design }\end{array}$ & $\begin{array}{l}\text { - } \quad \text { Computer-aided parametric product design that enable semi- } \\
\text { automatic customer specific product creation } \\
\text { - } \quad \text { Modular product structure, standardization of building blocks } \\
\text { - } \quad \text { Product family, platform design }\end{array}$ \\
\hline $\begin{array}{l}3 \text { PDP is integrated into PLM } \\
\text { workflow configuration }\end{array}$ & $\begin{array}{ll} & \text { Smooth data transfer inside PDP } \\
\text { - } & \text { Control mechanisms for data transfer between different modules } \\
\text { - } & \text { Integration between different software tools }\end{array}$ \\
\hline $\begin{array}{l}4 \text { Integration of external teams } \\
\text { into information system }\end{array}$ & $\begin{array}{l}\text { - Information connection between manufacturer and sub-suppliers } \\
\text { + Long-term strategic relationship }\end{array}$ \\
\hline $\begin{array}{l}5 \text { Integration of PDP and data } \\
\text { with other business processes }\end{array}$ & $\begin{array}{ll} & \text { Establish smooth workflow } \\
\text { - } & \text { Integration with ERP }\end{array}$ \\
\hline $\begin{array}{l}6 \text { Implementation of knowledge } \\
\text { management }\end{array}$ & $\begin{array}{l}\text { - Integration of new knowledge into tools and methods for PD } \\
\text { (recording of new findings, use of stored knowledge) } \\
\text { - } \quad \text { The creation of EC propagation maps on each product family } \\
\text { - } \quad \text { There is systemic knowledge generation; research work parallel } \\
\text { to running projects } \\
\text { - } \quad \begin{array}{l}\text { Research must run in parallel and new findings must be } \\
\text { integrated into design tools. }\end{array}\end{array}$ \\
\hline
\end{tabular}

\section{A case study: One-of-a-kind production of large power transformers}

A manufacturer is a typical representative of a one-of-a kind production. The sample company is a renowned manufacturer of large power transformers. The case study demonstrates how to organize IT support and create tools and methods for adaptive product design, for the creation of a product digital twin. The basic working principles as well as the peripheral functional requirements are known. Every design begins from the same baseline, which is the selection of the appropriate parametric 3D model layout. Parametric models consist of smart subassemblies and parts whose design is well considered and founded in the company's experience and knowledge, along with a number of standard components. Despite well-structured and content-rich parametric constructions, each new individual contract requires the modification of numerous details, which makes each final product unique. The individualization process includes 
the parametric change of advance prepared components and sometimes a certain degree of completely newly designed components. The human factor at this point is of great importance, as it directly affects the final number of detected or undetected errors. The aim is the elimination of the human factor within the limits of everyday engineering usability and economic viability. The authors of this paper argue that, on the basis of a systematic analysis of a development and design process, it is possible to establish a smart system of information and methodological support to reorganize activities such that they makes the adaptive design process robust, smart, and therefore effective.

Figure 1 summarizes specifics of adaptive design process in one-of-a-kind production. Tools and methods for agile product configuration and adaptive design is a framework that enable a fast and reliable response to customer specific requests. Basic research such as noise reduction runs in parallel to the projects aimed at realizing customer orders. The results of basic research are later integrated into design tools. The structure of IT support and the interconnection of different sources of information is the focus of this paper. It is important to ensure the security and integrity of information during a transfer between different sub-systems. Several tools were thus established for the faster execution of design activities, and for information sharing and reuse.

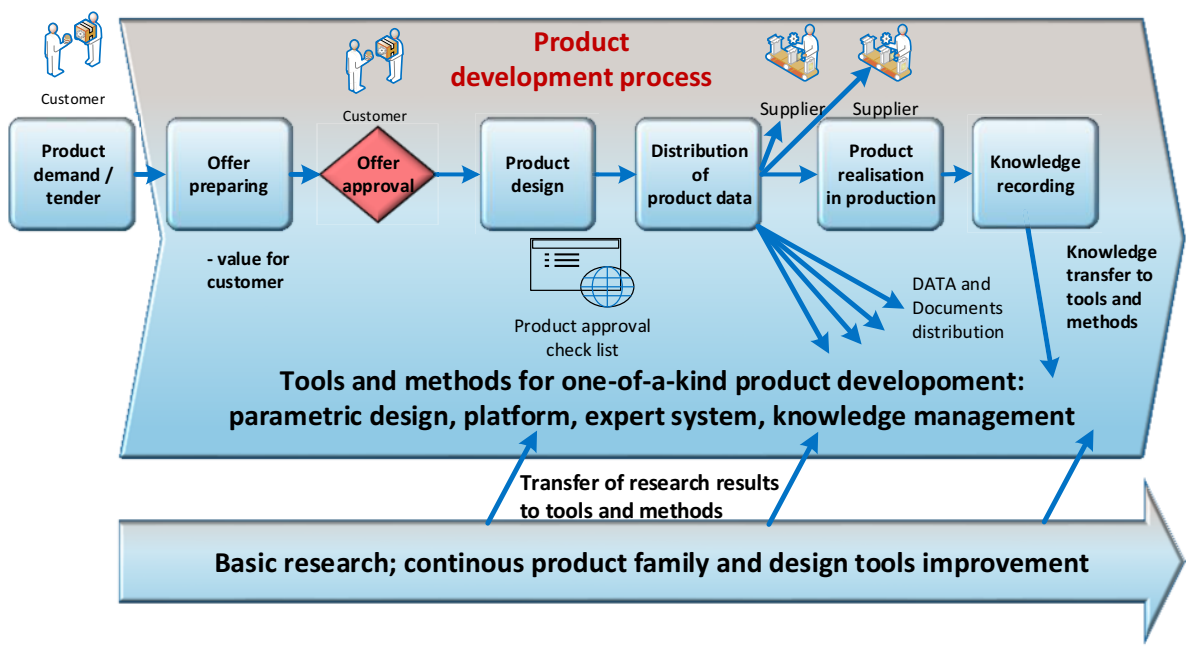

Figure 1. Generalized adaptive design process in one-of-a-kind production of complex products.

This paper's contribution is in the integrated product information model, the description of supporting tools, and the model of integration with the design processes of customized power transformers. The used approach of information management can be generalized and applied to other manufacturing companies. In the following sections specific IT supporting tools are presented: the expert system, parametric modelling, PD computer aided tools, and knowledge management.

\section{IT support and computer aided tools for PDP}

OKP products are customized solutions which satisfy the customer requirements with a high level of variety. A business strategy based on OKP products requires design tools for the efficient generation of product variants [14]. Usually, the design of OKP solutions 
such as complex engineering systems (e.g. power transformers) starts from a template configuration. In this context, the appropriate combination of design information that meets technical goals and customer requirements is the main challenge [15]. Albers et al. highlighted how a lack of tools still exists in the development of flexible and agile design methods to support optimized workflows [16].

\subsection{Internal standardization, modularity and platforming}

The reuse of previous solutions is well known in companies that produce customized and modularized products. Modularity was applied in this context to reusing pre-designed modules efficiently, greatly influencing the fields of adaptability, flexibility, and agility. One-of-a-kind products usually comprise three main groups of components. The core group includes characteristic components that define the product. They are individually adapted to certain project requirements via controlled process re-engineering. This means that any modification is made with special concern, as any changes to those components usually mean almost certain accommodations to adjacent, usually subordinated subsystems. In another group, components suitable for standardization are classified. Those components are usually very important for the agility of the entire process. Although they are usually not of great importance to customers, they simplify the product structure in terms of standardized solutions, especially in detailed design. The challenge is to reduce variation while preserving the creativity that is necessary for the creative process. Standardization enables the creation of highly stable and predictable outcomes with both high quality and precise timing in an unpredictable environment. Examples of standardized parts may include flanges, supports, lifting and lashing lugs, inspection openings, etc. The last group of components contains components suitable for the absorption of changes. Such components are typical for one-of-a-kind production since they increase customer-perceived value. Their numerousness generally dictates a product's market success.

A modular architecture encourages the development of self-contained and relatively independent (or loosely connected) assemblies or modules that can be detached, modified, relocated, and replaced easily. Because the modules in a modular product are relatively independent, these modules can be designed and manufactured separately. Modular design help in creating a range of products with minor variances and allows some components to be used across product variants and product lines due to standardization of the functions and interfaces.

Product platforming is a specific solution approach that focuses mainly on offering high product variety to customers while reducing development and manufacturing costs. Products sharing the same platform usually form a family of products. Platform design is considered as the extension of modular design by using the platform - the main module - in all the products of this family. In adaptable design, the functions of different products can be achieved using the platform design approach. When certain functions are required, the modules with these functions are then attached to the platform.

Subassemblies of power transformers are designed as scalable platforms with standardized connection interfaces. Changes between different modules can be made with ease, because parameters delivered into the master assembly via expert systems define the geometry on the top level of each platform. Excluding one module and activating another one usually has no serious influence on geometric stability of other adjacent platforms. Modules are attached to the platform with auto placement rules (Fig. 2 ). Rules are written into the module's parametric settings using designated coordinate 
systems, points, axes, or datum planes for navigation. Components that need to be flexible are designed to fully accommodate parametric sketches, which are the foundation of any scalable platform (see the cooling battery pipe frame).

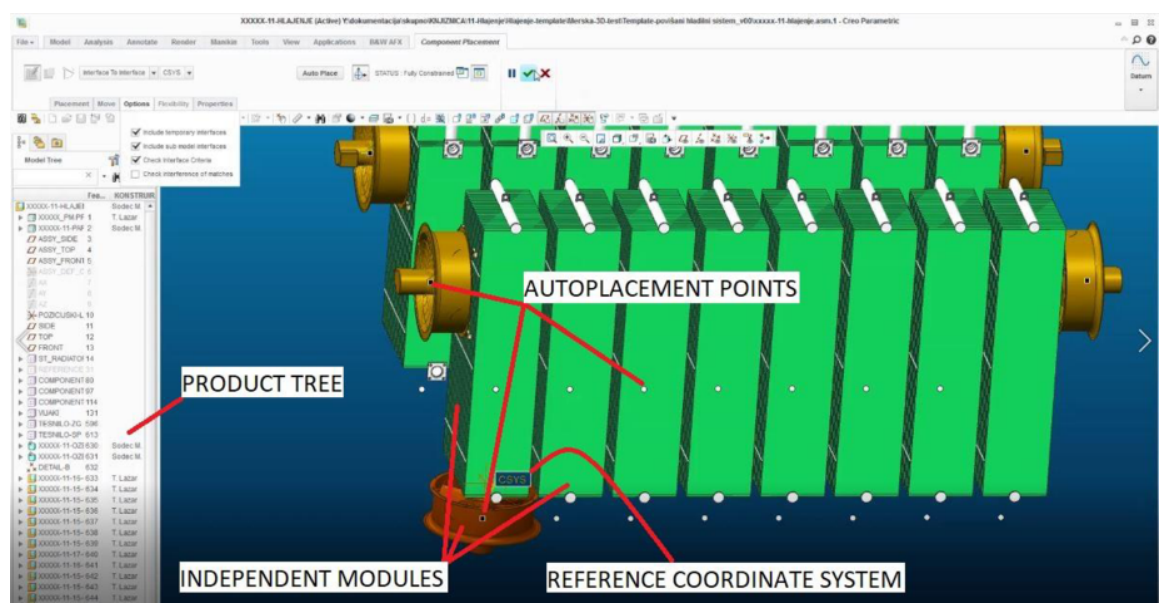

Figure 2. Smart auto placement rules with spatially oriented components enable easy and efficient change, addition, or deletion of components. Basic radiators on the ends of the cooling system were replaced with radiators with fan braces.

\subsection{Computer-aided tools for PDP and expert system}

The digital twin of complex one-of-a-kind products requires the optimization of advanced solutions where parameters are related to scalable and modular platforms. In this context, the integration between optimization tools and model-based simulations is necessary to manage the complexity. Computer Aided Engineering (CAE) tools are applied to compare the mechanical behavior of different OKP configurations and, therefore, they are involved into optimization loops [17]. In mechanical and electronic applications it is an important challenge to select feasible system architecture that satisfies both technical requirements and customer preferences [18].

Figure 3 presents the methodology framework: the input parameters are fundamental preconditions for preliminary design. In the case study these are electrical calculations about the power transformer, customer requirements, preliminary outline and transport drawing, tender data, equipment bill of material, etc. The general product architecture is defined in the preliminary design phase by selecting an appropriate platform for each product subassembly. Advanced parametric design enables an efficient configuration design process because all platforms are interchangeable due to their unified connecting interfaces. Parametric modularity also enables effective design iterations in the event of late design changes.

The internally developed expert system represents the core of the design activities and helps to manage the development of a product digital twin. It represents a functional link between preliminary design space, the knowledge database, and simulations (Fig. 3 ). The expert system enables the multilateral exchange of parameters and increases the robustness of the whole operation in the event of any redesign activities. An overview between numerical simulations and input/output parameters enables the chief design engineer to effectively conduct numerous calculations in a short time period. In addition 
to the basic information distribution it offers to some degree automated decision-making for appropriate design solutions. Expert systems include a database of the import parameters of all main subassemblies that links a structurally finite element analysis (FEM) and later design process in a parametric 3D environment. A comprehensive approach to problem solving that involves intensive simultaneous participation of key members of the project team is essential, in particular electrical and mechanical designers and development engineers. Functional links and progress bars eliminate human errors completely. When introduced, product development and design process made a considerable step towards robust and effective operation. The data field necessary for the realization of the entire activity was reduced by about $50 \%$ on both the input and output side. Estimated time savings have been recorded of between $15 \%$ and $20 \%$.

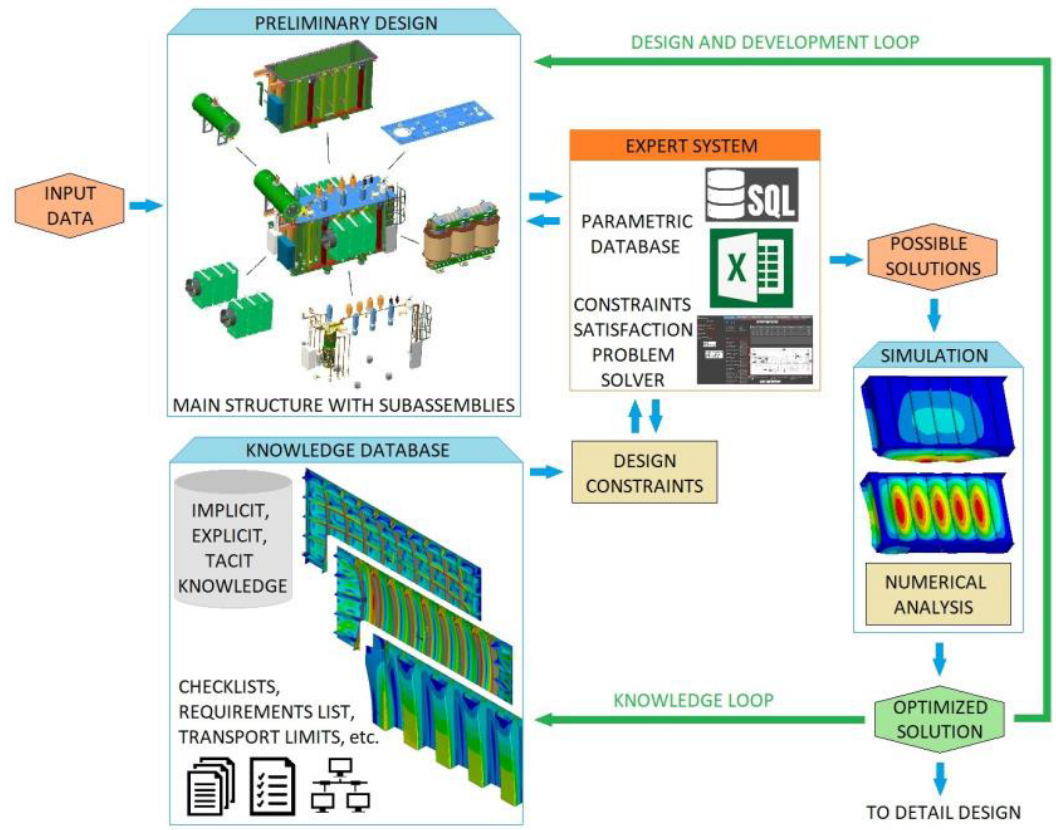

Figure 3. The proposed initial design methodology framework.

\subsection{Knowledge management}

Proper recording of information should be a part of regular work and not a matter of the engineers' good will at the end of a project. It means that each project, each engineering change (EC) should include the documents, such as design and process FMEA, product history file, and 8D reports with important information. Proper recording of knowledge shall start in PDP, while most knowledge is created during this phase. Recording of new findings needs to continue through the whole exploitation phase of the product life cycle [19]. Customer complaints and new modes of failures from the market are very valuable pieces of information that were not known at the time of PD.

Documents should be available in a central database such as a PLM system and accessible through a user-friendly classification and searching tool. Human-based KM is an acceptable solution for smaller companies with minimal personnel fluctuations. In larger systems with several hundred employees, a systematic recording of knowledge is 
of utmost importance. Employees must have competencies for systematic work in teams and for recording knowledge in a structured manner; this later becomes a prerequisite for searching. Well-recorded decisions, an explanation of important details, and structured and self-explanatory presentations of data also facilitate the search for and reuse of information for engineers on other teams [13]. An enterprise should foster and promote a culture of knowledge sharing, the permanent recording of knowledge, and its reuse.

Knowledge management consists of five core activities: capture, validation, storage, retrieval, and reuse (Fig. 4). Knowledge stored in documents is used as a resource for better conduct of activities. An organization must enable work in interdisciplinary teams that encourage knowledge creation and sharing.

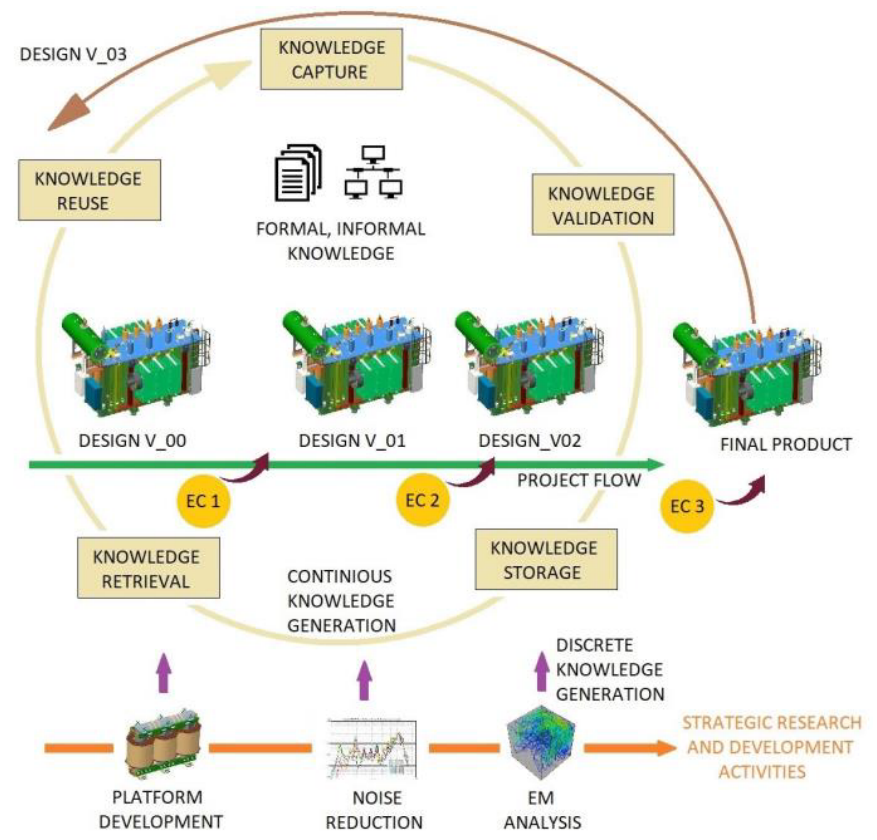

Figure 4: A framework for integrated knowledge management in OKP. After last minute changes before product delivery, project is always reviewed and corrected in case of possible repetitions in the future.

\section{Discussion}

This paper has presented the transformation of product development design for large power transformers into a competitive and smartly supported process. One-of-a-kind production has its own rules and specifics, as all design activities and efforts are influenced by completely customized products for known clients. Therefore, a robust design process well supported by IT plays a key role in creation of a digital twin and the product's final value. Based on a systematic analysis of the sample company, the paper proposed a model for the complete renewal of information system and working methodology, where reorganization was demonstrated in an increase of overall effectiveness.

Design for changeability, a design strategy developed to cope with engineering changes, incorporates the following four aspects: adaptability, robustness, agility, and 
flexibility. System architectures characterized by these attributes will yield great enhancements. It is possible to insert technology throughout the entire system lifecycle to ensure superior system capabilities and customized functionality. Opportunities for upgrade and ease of customization lead to high levels of attractiveness for customers or stakeholders. Design reuse aims to maximize the value of customization efforts by reusing successful past digital twins in whole or in part for future designs. More often than not, when a new design problem arises, it is solved through the modification of an existing design rather than performing the design process from scratch. Due to the complexity, associated cost, and general uncertainty of performing the creative design process, significant value exists in reusing design information. This paper's valuable contribution is the framework for integrated knowledge management in OKP. After lastminute changes and before the delivery of any one-of-a-kind product, the project is always reviewed and corrected for potential future repetitions, even if they are not expected. Knowledge for any new product is hidden in knowledge and experiences, gained during accomplished past products.

The conducted research demonstrates that the issue at hand is complex, wherefore its professional breadth requires the cooperation of the entire company. Constraints satisfaction problem (CSP) solver, developed internally by R\&D department, has proved to support an initial stage of customized product design to a great degree. When introduced, the product development and design process made a considerable step towards robust and effective operation. The solver merged numerous structural calculations that were, up to that point, organized as separate independent spreadsheets. With functional links between all calculation chapters and the flow of parameters (input/output), the solver enables numerous calculations in a short time period. Functional links and progress bars eliminate human errors completely. Figure 3 presents the proposed initial design methodology framework. Defined input parameters are fundamental preconditions for preliminary design. In the preliminary design phase the general product architecture is defined by selecting an appropriate platform for each product subassembly.

\section{Conclusions}

The results of the presented IT support upon creation of the digital twin in the PD process are promising in multiple aspects and offer various opportunities for further development. Advanced parametric design enables an efficient configuration design process because all platforms are interchangeable due to their unified connecting interfaces. Parametric modularity also enables effective design iterations in the event of late design changes. The expert system forms the core of design activities and enables multilateral exchange of the parameters, increasing the robustness of the whole operation in the event of any redesign activities.

A direct consequence of implied renovation are savings, which were obtained in the performance analysis during a one-year test period. The total design time for product customization was reduced from 40 to 23 hours, especially the time necessary to complete a 3D design of the featured assembly (magnetic core), namely from 16 to 5 hours. The number of realized projects per year (per person) was increased by $33 \%$. At the same time, the percentage of realized projects where engineering changes were necessary (rework) was reduced from 5 to $1 \%$. The proposed framework is generalized, making it directly applicable in similar business environments and thus helpful for 
establishing the best-practice guidelines for promoting competitiveness in one-of-a-kind PD processes.

\section{References}

[1] G. Letens, J.A. Farris, E.M. van Aken, A multilevel framework for lean product development system design, Engineering Management Journal, 2011, Vol. 23, No. 1, pp. 69-85.

[2] P. Zheng, C.-H. Chen, S. Shang, Towards an automatic engineering change management in smart product-service systems - A DSM-based learning approach, Advanced Engineering Informatics, January 2019, Vol. 39, pp. 203-213.

[3] J. Riezebos, and W. Klingenberg, Advancing lean manufacturing, the role of IT, Computers in Industry, 2009, Vol. 60, No. 4, pp. 235-236.

[4] M. Varl, J. Duhovnik, J. Tavčar, Towards a model for robust design and design process in one-of-a-kind production of large power transformers, International Journal of Agile Systems and Management, 2016, Vol. 9, No. 1, pp. 67-88.

[5] J. Stark, Product Lifecycle Management (Volume 3): The Executive Summary, Springer International Publishing AG, 2018.

[6] W. Liu, and Y. Zeng, Conceptual modelling of design chain management towards product lifecycle management, Proceedings of the 16th ISPE International Conference on Concurrent Engineering, Springer, London, 2009, pp.137-148.

[7] S. Rogalski, Factory design and process optimization with flexibility measurements in industrial production, International Journal of Production Research, 2012, Vol. 50, No. 21, pp. 6060-6071.

[8] B.P. Nepal, O.P. Yadav, and R. Solanki Improving the NPD process by applying lean principles: a case study, Engineering Management Journal, 2011, Vol. 23, No. 3, pp. 65-81.

[9] D. Reinertsen, and L. Shaeffer, Making R\&D lean, Research Technology Management, Industrial Research Institute, Inc. , 2005, Vol. 48, No. 4, pp. 51-57.

[10] Z. You, C. Wu, A framework for data-driven informatization of the construction company, Advanced Engineering Informatics, January 2019, Vol. 39, pp. 269-277.

[11] J. Tavčar, I. Demšar, J. Duhovnik, Engineering change management maturity assessment model with lean criteria for automotive supply chain, Journal of Engineering Design, April 2018, Vol. 29, No. 4/5, pp. 235-257.

[12] S. Shafiee, L. Hvam, A. Haug, M. Damc, K. Kristjansdottir, The documentation of product configuration systems: A framework and an IT solution, Advanced Engineering Informatics, April 2017, Vol. 32, pp. $163-175$.

[13] J. Tavčar, J. Benedičič, R. Žavbi, Knowledge management support in the engineering change process in small and medium-sized companies, International Journal of Agile Systems and Management, 2019, Vol. 12, No. 4, pp. 354-381.

[14] F. Elgh, Decision support in the quotation process of engineered-to-order products, Advanced Engineering Informatics, Jan. 2012, Vol. 26, No. 1, pp. 66-79.

[15] B. Stump, and F. Badurdeen, Integrating lean and other strategies for mass customization manufacturing: a case study, Journal of Intelligent Manufacturing, 2012, Vol. 23, No. 1, pp.109-124.

[16] A. Albers, M. Spadinger, M. Serf, S. Reichert, S. Heldmaier, M. Schulz, and N. Bursac, Coupling of Computer-Aided Methods: Supporting Product Developer During Embodiment Synthesis, Advances in Structural and Multidisciplinary Optimization, 2017, pp. 536-548.

[17] R. Wang, A. B. Nellippallil, G. Wang, Y. Yan, J. K. Allen, and F. Mistree, Systematic design space exploration using a template-based ontological method, Advanced Engineering Informatics, April 2018, Vol. 36, pp. 163-177.

[18] K. Gadeyne, G. Pinte, and K. Berx, Describing the design space of mechanical computational design synthesis problems, Advanced Engineering Informatics, Aug. 2014, Vol. 28, No. 3, pp. 198-207.

[19] P. Gongzhuang, W. Hongwei, Z. Heming, H. Keke, A hypernetwork-based approach to collaborative retrieval and reasoning of engineering design knowledge, Advanced Engineering Informatics, October 2019, Vol. 42, 100956. 